Benjamin Constant

Euvres complètes

Euvres

I 


\section{Benjamin Constant Euvres complètes Série Euvres I}

\section{Comité directeur}

Président: Paul Delbouille

Jean-Daniel Candaux, C. P. Courtney, Alain Dubois, Étienne Hofmann, Norman King, Kurt Kloocke, Lucia Omacini,

Claude Reymond et Dennis Wood

\section{Conseil scientifique}

Président: Alain Dubois - Secrétaire: Étienne Hofmann

Membres d'honneur: Jean-Charles Biaudet, Roland Mortier, Claude Reymond, $\uparrow$ Patrice Thompson Membres:

Simone Balayé, André Cabanis, Maurice Déchery, Pierre Deguise, Michel Delon, Françoise Fornerod, Doris Jakubec, Béatrice Jasinski, François Jequier, Mario Matucci, François Rosset,

Corrado Rosso, Martine de Rougemont, Lionello Sozzi, Arnaud Tripet, Markus Winkler, Dennis Wood ainsi que les membres du Comité directeur

Ce tome I appartient à la première période (1774-1799) dirigée par Jean-Daniel Candaux

La révision en a été assurée par François Rosset

La supervision du traitement informatique a été prise en charge par Kurt Kloocke 


\title{
Benjamin Constant
}

\section{Écrits de jeunesse \\ (1774-1799)}

\author{
Volume dirigé par \\ Lucia Omacini et Jean-Daniel Candaux
}

Textes établis et annotés par

Mauro Barberis

et par Simone Balayé, Claude Bruneel, Magda Campanini, Paul

Delbouille, Edouard Guitton, Roland Mortier et Claude

Reymond ; avec des notices de Mauro Barberis, Jean-Daniel

Candaux, Kurt Kloocke et † Patrice Thompson

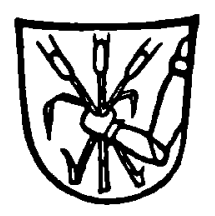

Max Niemeyer Verlag

Tübingen 1998 
Die Deutsche Bibliothek - CIP-Einheitsaufnahme

Constant de Rebecque, Benjamin de: Euvres complètes / Benjamin Constant. - Tübingen : Niemeyer.

Sér. Euvres.

1. Écrits de jeunesse (1774-1799) / vol. dir. par Lucia Omacini et Jean-Daniel Candaux. Textes établis et annot. par Mauro Barberis ... - (1998)

ISBN 3-484-50401-3

(c) Max Niemeyer Verlag GmbH \& Co. KG, Tübingen 1998

Das Werk einschließlich aller seiner Teile ist urheberrechtlich geschützt. Jede Verwertung außerhalb der engen Grenzen des Urheberrechtsgesetzes ist ohne Zustimmung des Verlages unzulässig und strafbar. Das gilt insbesondere für Vervielfältigungen, Übersetzungen, Mikroverfilmungen und die Einspeicherung und Verarbeitung in elektronischen Systemen.

Printed in Germany.

Satz: pagina $\mathrm{GmbH}$, Tübingen

Druck: Allgäuer Zeitungsverlag GmbH, Kempten

Einband: Norbert Klotz, Jettingen-Scheppach 